\title{
Fake news, pós-verdade e os limites (ou desafios) da opinião pública na sociedade da plataforma
}

Fake news, post-truth and the limits (or challenges) of public opinion in the platform society

Noticias falsas, post-verdad y los límites (o desafíos) de la opinión pública en la sociedad de la plataforma

\section{Bruno Kegler}

- Docente do Departamento de Gestão de Negócios e Comunicação da Universidade de Santa Cruz do Sul (UNISC).

- Pós-doutorando no Programa de Pós Graduação em Comunicação da Universidade Federal de Santa Maria (POSCOM/UFSM).

- Doutor em Comunicação e Informação pela Universidade Federal do Rio Grande do Sul (UFRGS).

- Publicitário e mestre em Comunicação pela UFSM.

- Membro do grupo de pesquisa Comunicação e Política.

- E-mail: brunokegler@gmail.com

(9) Rejane de Oliveira Pozobon

- Docente do Programa de Pós-graduação em Comunicação da UFSM.

- Professora Associada do Departamento de Ciências da Comunicação da UFSM.

- Doutora em Ciências da Comunicação pela Universidade do Vale do Rio dos Sinos (Unisinos).

- Mestre em Educação pela UFSM.

- Bacharel em Jornalismo e em Relações Públicas pela UFSM.

- Líder do Grupo de Pesquisa Comunicação e Política.

- E-mail: rejanepozobon@gmail.com 


\section{Resumo}

0 artigo traz uma reflexão sobre a produção da opinião pública na sociedade de plataformas, apontando como os fenômenos das fake newse da pós-verdade incidem sobre esse processo. Para tanto, traça um panorama da lógica comunicativa vigente e aciona o conceito de opinião pública para pensar as especificidades e as nuances do debate público em plataformas on-line.

\section{PALAVRAS-CHAVE: OPINIÃO PÚBLICA •SOCIEDADE DA PLATAFORMA•FAKENEWS•PÓS-VERDADE.}

\section{Abstract}

The article presents a reflection about the production of public opinion in the platform society, showing how the phenomena of fake news and post-truth focus on this process. For this, it draws a panorama of the current communicative logic and uses the concept of public opinion to think about the specifics and nuances of public debate on online platforms.

\section{KEYWORDS: PUBLIC OPINION • PLATFORM SOCIETY • FAKE NEWS • POST-TRUTH}

\section{Resumen}

El artículo reflexiona sobre la producción de opinión pública en la sociedad de la plataforma, señalando cómo los fenómenos de noticias falsas y post-verdad se centran en este proceso. Para hacerlo, dibuja una visión general de la lógica comunicativa actual y activa el concepto de opinión pública para pensar en los detalles y matices del debate público en las plataformas en línea.

\section{PALABRAS CLAVE: OPINIÓN PÚBLICA・SOCIEDAD DE PLATAFORMA・NOTICIAS FALSAS・POST-VERDAD.}

\section{CENÁRIO DE ANÁLISE}

A comunicação digital e os avanços tecnológicos acionam uma nova lógica de produção da informação e, consequentemente, da opinião pública. Nessa perspectiva, as mídias tradicionais e os formadores de opinião convencionais passam a disputar espaço com outros enunciadores de informação. A opinião pública, por sua vez, passa a ser construída por uma pluralidade de atores que, munidos de tecnologia e em muitos momentos de informações controversas, promovem uma lógica comunicativa ancorada em temas de interesse público e submetida ao modus operandide plataformas on-line de propriedade privada.

Com isso, não se trata apenas de buscar compreender a dinâmica e os fluxos comunicacionais dessas plataformas e, assim, parte essencial do debate constituinte da opinião pública. Para além disso, trata-se de reconhecer que as plataformas não são construções neutras, pois têm normas e valores específicos inscritos em suas arquiteturas e que, por conseguinte, 0 debate público é submetido às suas premissas ideológicas. Ademais, nesse horizonte, considera-se que seu funcionamento tem implicações sociais e funções organizativas ante sua infiltração gradual nas instituições e práticas em torno das quais se estruturam as sociedades democráticas na contemporaneidade. 
Esse contexto é denominado por Van Dijck (DIGILABOUR, 2019) de "sociedade de plataformas", noção que sinaliza para a canalização do tráfego social e econômico para um ecossistema', corporativo e global, de plataformas on-line, orientado por algoritmos e alimentado por dados. Embora haja assimetria entre as plataformas, as de grandes corporações coexistem e concorrem com as de governos, consumidores e cidadãos, corporações, empresas de mídia e de notícias, organizações não governamentais (ONGs), e que, portanto, também fazem parte da modelagem das práticas sociais e econômicas.

É diante desses pressupostos que esse texto se encaminha, propondo a reflexão acerca dos limites e das possibilidades para a constituição da opinião pública contemporânea, acionando também os termos fake news e pós-verdade. A compreensão conceitual sobre fake news segue Dourado e Gomes (2019, p.1), enquanto "histórias sobre fatos inventados ou propositalmente alterados para fins políticos". Como afirmam os autores, nesse contexto é necessário prescindir da verdade, para que se origine uma nova expressão cognitiva que reascende debates já superados pela racionalidade. Assim, para ilustrar, há a proliferação de teorias conspiratórias, crenças estranhas e retrógradas, além de questionamentos a saberes científicos consagrados, tais como o terraplanismo ${ }^{2}$ e as dúvidas quanto à existência e as consequências do aquecimento global e à eficácia das vacinas, em escala sem precedentes, sobretudo pela reverberação em plataformas on-line.

Esse fenômeno nos conduz à noção de pós-verdade. Para Alexis Wichowski (2020), o que visualizamos hoje é o fato de muitas pessoas ignorarem determinados acontecimentos e a própria realidade em favor de suas opiniões ou perspectivas pessoais. A autora relembra que as pessoas sempre ignoraram fatos que as deixassem desconfortáveis, mas a internet possibilitou que elas encontrassem outros indivíduos que pensam de forma semelhante. Ficou mais fácil encontrar a "verdade" que nos é conveniente. Como observam Sacramento e Paiva (2020, p.4), cada vez mais, com a centralidade da internet, "circulam informações e práticas discursivas que concorrem com as oficiais, ao se autoproclamarem como portadoras da verdadeira verdade". Essas práticas são consonantes com um processo em curso de generalização da desconfiança com as instituições que tradicionalmente ancoram a democracia, dentre as quais estão as estatais e as de imprensa. Nesse sentido, pós-verdade se caracteriza como "verdade contextual, que não pode ser escrita, posta no bolso e representada amanhã, como garantia de fidelidade, compromisso ou esperança gerada pela palavra (DUNKER, 2017), com impactos políticos, morais, nos laços pessoais, nas formas de amar e de sofrer.

Compreendemos, assim, que sociedade de plataformas (VAN DIJCK; POELL; DE WALL, 2018), fake news (DOURADO; GOMES, 2019) e pós-verdade (DUNKER, 2017) formam uma constelação conceitual afeita à discussão sobre a constituição da opinião pública. Para finalizar, buscando uma perspectiva mais pragmática para a definição do processo de formação da opinião pública, encontramos o aporte teórico em Lippmann (2010), que insere os processos de formação da opinião no horizonte do que denomina de pseudoambiente, constituído por imagens da realidade, criadas (também) pela mídia, pelos quais os mapas mentais, de indivíduos e coletividades, são formados e administrados.

0 conhecimento da realidade é, nessa perspectiva, indireto, a partir de imagens reconhecidas como verdadeiras e, por isso, tratadas como se o próprio ambiente. Permite tensionar, portanto, os pontos de encontro e de desencontro entre o mundo que as pessoas conhecem e o mundo que elas poderiam ter conhecido se tivessem presenciado o acontecimento. Ou, em complemento, se confiassem nas versões das instituições legitimadas a conferir veracidade às informações sobre os fatos.

Está em tela, diante dessas considerações, as disputas estabelecidas em torno da opinião, em plataformas on-line, considerandose o uso estratégico de recursos que são da ordem do discurso e da estética midiática, mas também os condicionamentos

1 Para Van Dijck, Poell e De Wall (2018), ecossistema de plataforma é formado por plataformas em rede, que são governadas por um conjunto específico de mecanismos que moldam as práticas cotidianas. 0 ecossistema ocidental é dominado, principalmente, pelas empresas Google, Apple, Facebook, Amazon e Microsoft.

2 Movimento formado por pessoas que acreditam que a Terra é plana. 
impostos pela organização das sociedades contemporâneas em torno de plataformas corporativas, cuja arquitetura e lógica de funcionamento respondem a premissas ideológicas mercantis, que passam a reger a ação e o comportamento das demais instituições, públicas ou privadas, participantes e concorrentes no debate público. Além desta introdução, o artigo contém uma seção teórica principal onde propomos o diálogo conceitual entre fake news, pós-verdade, sociedade de plataformas e opinião pública, além das considerações finais.

\section{SOCIEDADE DE PLATAFORMAS, PÓS-VERDADE E FAKE NEWS: UM DEBATE SOBRE A OPINIÃO PÚBLICA POSSÍVEL}

Do ponto de vista dos usuários, a oferta e a seleção de informações através de plataformas parecem mais horizontal, mais democrática, do que a realizada pelas corporações midiáticas tradicionais, tendo-se em vista que há um processo de retroalimentação conforme a interação do usuário com a plataforma. Quanto mais se busca sobre um assunto, ou a partir de alguma fonte de informação, graças à ação de algoritmos, plataformas como o Facebook programam e personalizam essa oferta ao usuário. Nesse sentido, hipoteticamente, pessoas que têm orientações ideológicas opostas terão em suas timelines versões também opostas sobre um mesmo tema político. No entanto a seleção não é moldada apenas pelas práticas do usuário, que tem algum controle sobre suas interações e informações por meio de recursos que permitem, por exemplo, bloquear outros usuários ou publicações, mas não se estendem aos critérios e às lógicas de seleção e de personalização da plataforma, as quais respondem a estratégias tecno-comerciais que permanecem reservadas às corporações que detêm sua propriedade (DIGILABOUR, 2019; VAN DIJCK; POELL; DE WALL, 2018).

Interesses, desejos e necessidades de cada usuário são determinados algoritmicamente com base nos dados gerados pelos sinais deixados durante a interação com a plataforma ou o ecossistema em que a plataforma está inserida. Assim, a personalização ocorre por meio da análise preditiva, ou seja, a capacidade de prever escolhas e tendências está ancorada na avaliação e comparação de padrões históricos de dados individuais ou agregados. Esses dados, mercantilizados, tornam-se estratégicos para anúncios publicitários, mas não somente isso - podem servir à proliferação de conteúdos da política e ao impulsionamento da desinformação. Como explicam Van Dijk, Poell e De Wall (2018), embora a mercantilização do usuário e a da plataforma se reforcem mutuamente, há disparidade nas relações de poder, pois o controle das interfaces, dos algoritmos e fluxos de dados permanece com os operadores de plataformas.

Além disso, ainda que governos e ONGs possam operar suas próprias plataformas, sua autonomia esbarra na dependência dos serviços de informação das cinco principais plataformas do ecossistema ${ }^{3}$, assim como dos recursos que lhe são inerentes. Isso porque plataformas públicas precisam contar com o Facebook e o Google para serem mais bem ranqueadas - tornarem-se mais visíveis -e alcançar grupos mais expressivos de usuários. Não há, nesse sentido, um espaço público on-line, visto sob a ótica ideal ou normativa no ecossistema corporativo. Há, sim, paradoxalmente, dependência de governos e instituições públicas da infraestrutura do ecossistema de plataformas on-line, privadas, para seu funcionamento, o que, de fato, é uma variável condicionante.

Na mesma direção, nas mídias tradicionais as organizações conectavam leitores e espectadores com anunciantes. Nas plataformas on-line, passaram a conjugar a necessidade de monetizar seu conteúdo por meio dos mecanismos de mercantilização impostos pela própria plataforma. Há, portanto, outros modos de enunciação, de interação e de leitura, mesmo para as notícias, subordinados à lógica comunicacional mercantilizada que está intrínseca a sua arquitetura e que são condicionantes da visibilidade e, consequentemente, da constituição do debate e da formação da opinião pública.

30 argumento do autor é que existem cinco empresas - Apple, Amazon, Google, Facebook e Microsoft - que detêm a infraestrutura de rede que todas as outras empresas, serviços, instituições e órgãos têm que, de alguma forma, utilizar para poder oferecer um produto ou usufruir de uma tecnologia. 
Conforme esclarece Lippmann (2010), a opinião reúne um conjunto amplo de variáveis que não são passíveis de observação direta em sua integralidade. Portanto a opinião é formada pela junção de retalhos e a relação entre eles, que não são, necessariamente, objetivos, pois nesse processo intervêm os preconceitos e os estereótipos que fornecem a angulação com a qual os fenômenos são observados. Nesse sentido, o conhecimento que se tem sobre os eventos, na maior parte das vezes, é indireto, derivado de relatos de quem presenciou ou teve acesso à sua descrição.

No âmbito das plataformas on-line, para além dessa relação entre quem fala e quem ouve e os modos como quem ouve representa o evento a partir da descrição de quem diz, há um entre que diz respeito ao emaranhado tecnológico que condiciona o que é visto e por quem será visto, por definição algorítmica. Além de personalizarem quais informações cada usuário irá receber, os mecanismos de seleção de plataforma identificam tendências de interesse dos usuários. Exemplo disso é a lista de tópicos de tendência oferecida pelo Twitter. Ao "retwitarem" mensagens massivamente, os usuários aumentam a visibilidade dessas mensagens, ranqueando-as nos tópicos de tendência e, consequentemente, ascende-se sua relevância ante a comunidade. Nesse cenário, seguidores falsos e "amigos" do Facebook são comercializados para inflar os dados de visibilidade e de reputação, manipulando-se a percepção acerca de pessoas ou temas comentados e, no limite, os processos de formação da opinião.

Pode haver aí o superdimensionamento da correspondência das crenças e das convicções, criando-se o clima de opinião e o efeito de espiral do silêncio, nos termos de Noelle-Neumann (1993). Em suma, o primeiro consiste na crença da existência de dois campos políticos distintos e na estimativa de força de cada um deles e de suas chances de sucesso numa disputa eleitoral. Nessa direção, a autora parte da premissa de que o indivíduo quer pertencer ao lado que ele reconhece como vencedor, motivado pela intenção de evitar o isolamento social, gerando o fenômeno da espiral do silêncio, que prevê que as pessoas cujas convicções são consonantes com as do lado supostamente derrotado tendem a não expressar sua preferência, mantendo-se em silêncio e contribuindo para a derrota de seu campo. Em contrapartida, aqueles que se sentem identificados com o lado supostamente vencedor tendem a verbalizar a opinião e a motivar outras pessoas a fazerem o mesmo. Nessa

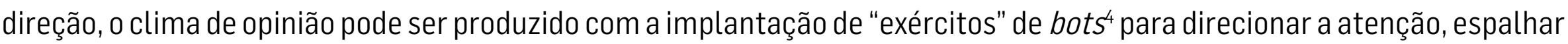
fake news e até mobilizar pessoas para manifestações offline.

Pode-se compreender, nessa linha, o que expõe Wichowski (2020) sobre a polarização política nos Estados Unidos. Para a autora, apesar de aparentemente existir uma divisão que se estende a toda a população, há uma "maioria exausta", silenciosa, e os "poucos zangados", barulhentos e que dominam o discurso público, desempenhando um papel crucial na formação da opinião pública. Nesse sentido, a polarização dicotômica nacional seria apenas aparente, pois o domínio de postagens na plataforma Twitter está concentrado em $10 \%$ dos usuários, que são responsáveis por $80 \%$ do total diário de publicações. Ou seja, grupos de extrema esquerda e de extrema direita, que representam apenas 14\% da população norte-americana, fazem o "barulho" suficiente para fazer parecer ser uma manifestação massiva. Portanto, se, de um lado, a visibilidade fala, por outro, a invisibilidade também é determinante no processo de formação de opinião.

Diante desses aspectos relacionados ao funcionamento das plataformas on-line e à construção da opinião, é razoável endossar a afirmação de Van Dijck, Poell e De Wall (2018) de que as instituições políticas, científicas e midiáticas, públicas ou privadas, antes instadas a ancorar a confiança e a sustentar o sistema democrático, precisam compreender como atuar em uma sociedade de plataformas, reconhecendo-se as premissas ideológicas, o funcionamento e as implicações sociais das funções organizativas ocupadas pelas plataformas nas sociedades contemporâneas.

4 Boté o diminutivo de robot, uma aplicação de software criada para simular ações humanas, repetidas vezes. Também é chamado de internet robot e de web robot. 
Seguindo nossa argumentação, ao acionarmos a noção de fake news, estamos abordando um tipo específico que não representa a totalidade dos processos comunicacionais estabelecidos em plataformas on-line, que se torna relevante pelo seu potencial de difusão e impacto - maléfico - no debate público contemporâneo e nos processos de produção da opinião pública. Nessa discussão, esses aspectos são articulados com o domínio das lógicas de visibilidade e de personalização das plataformas on-line.

Como indicam Dourado e Gomes (2019, p.2), "há cada vez mais reivindicações de verdade e há cada vez mais mentiras no que se refere a histórias políticas", sendo a verdade ou a falsidade relacionada à possibilidade de que narrativas factuais expressem ou não os fatos reais a que fazem a referência. Há, nesse escopo - mas não somente isso -, relatos camuflados de notícias, ancorados na autoridade e na credibilidade do jornalismo, mas que falseiam os fatos narrados. Para os autores, devem ser entendidos como sintomas de um "fenômeno, que começa com o ataque sistemático à credibilidade das instituições "credenciadas" para determinar o que é verdadeiro e que aconteceu de fato e termina com a admissão de uma epistemologia tribal de que verdade e falsidade são relativas aos interesses da nossa tribo" (DOURADO; GOMES, 2019, p.24). Trata-se de uma ação deliberada justamente para distorcer a realidade e assim obter algum ganho eleitoral ou a adesão às suas ideias.

Na mesma perspectiva de Dourado e Gomes (2019), Wichowski (2020) indica que fake news são elementos estratégicos e a proliferação de falsas alegações em mídias sociais seria projetada para minar o senso de segurança, a compreensão da realidade e, consequentemente, a estabilidade da própria democracia. A polarização política e social seria tributária do medo que as pessoas sentem de que outras obtenham o que elas não terão, por isso é um processo que leva ao sentimento de desconexão, ao distanciamento social.

Os efeitos das fake news podem ser compreendidos à luz de Lippmann (2010), quando diz que as pessoas respondem à ficção tanto quanto à realidade, adicionando, aí, a capacidade criativa de elaborar as próprias ficções às quais elas respondem, e desafia "que atire a primeira pedra quem nunca passou adiante como verdade aquilo que ouviu dizer, sendo que quem 0 disse não sabia mais do que ele" (p.30). Daí que uma pessoa muito religiosa passe a defender a guerra ou a morte de pessoas que mantêm relações homoafetivas, segundo seu código moral, enquanto esquema de conduta, seja ele familiar, patriótico, político, religioso ou outro.

Essa mesma capacidade de transitar no binômio realidade/ficção é possível de ser observada na noção de pós-verdade. 0 termo "inaugura uma reflexão prática e política sobre o que devemos entender por verdade e sobre a autoridade que lhe é imposta" (DUNKER, 2017, p.13), assim como a pós-modernidade teria trazido o debate sobre como deveríamos entender a modernidade e o sujeito moderno. Há, na noção de pós-verdade, a reafirmação dos valores da modernidade, sobretudo quanto à racionalidade, por meio do resgate de aspectos pré-modernos da verdade, que é moralmente potente e que traz consigo "as prerrogativas estéticas do gosto e com a força política das religiões" (DUNKER, 2017, p.18).

Para Sacramento e Paiva (2020), as redes de comunicação on-line se hibridizam com outros processos de socialização já existentes, tais como as crenças religiosas. Desse modo, a confiança nas informações circulantes estaria mais na ordem da convicção do que da persuasão, e a questão das fake news e da pós-verdade estaria estruturada pela mudança das relações entre crença e convicção, diluindo-se as fronteiras entre crença e verdade, de modo que

acreditar que, desempenha uma relação intensa com o acreditar em, próprio da convicção, envolvendo o sujeito num compromisso com um sistema simbólico de explicação do mundo que lhe dá segurança ontológica, mas que, ao mesmo tempo, convenceu-0 e deu-lhe certeza e confiança para lidar com a própria existência. (SACRAMENTO; PAIVA, 2020, p.10) 
Assim, referem-se à criação de uma ambiência que orienta os modos de sentir, de viver, ancorada em uma lógica mais emocional e performática, mais subconsciente do que consciente. Diferentemente dos jornais e da publicidade, que mesmo tendo sempre buscado a captura da atenção do leitor|consumidor e se utilizado de lógicas implícitas de facilitação da leitura, estavam estruturados sobre os pilares da retórica argumentativa. Por outro lado, o prevalecer da convicção relaciona-se com a aceitação imediata pelo interlocutor, reduzindo-se a possibilidade de persuasão, mesmo para temáticas que envolvam vida e morte, como uma pandemia de dimensões intercontinentais. A partir de Lippmann (2010), pode-se ler essa perspectiva no horizonte dos códigos e estereótipos que constituem o pseudoambiente ao qual o indivíduo responde.

Em consonância, Dunker (2017) diz que a ancoragem da verdade, hoje, estaria menos na profundidade e na consistência da argumentação, mesmo que por meio da apresentação de provas e demonstração de especialista; e mais na sapiência de quem está falando, com seu carisma e estilo. Além disso, passa pela administração calculada da memória, pois a última palavra e o consenso (aparente) momentâneo são o que importa, junto da perspectiva imediatista da resolução de qualquer conflito. Nesse sentido, o reforço das convicções prevalece ao processo de mudança de opinião, que requer o exercício da crítica, da comparação e da troca exaustiva de argumentos. Declarações de impacto e que, de alguma forma, menosprezam e contradizem especialistas e dados científicos, passam a ter relevo, e a educação acrítica, por exemplo, passa a ser - enquanto meta, ao menos - 0 ensaio para a constituição performática da realidade.

Nessa direção, a gênese da pós-verdade passaria pela assunção das tecnologias digitais como autoridade moral em que tudo se comunica, sem barreiras, "por meio de esquemas holistas e integrativos para mostrar que, se permanecermos juntos, confortáveis e amados, tudo terminará bem" (DUNKER, 2017, p.22). Portanto é parasitária à educação e traz consigo valores ligados à família e à figura do pai-chefe eficiente e administrador, em recusa à política. Posto "do outro lado", o processo educativo é visto como manipulatório, sob a acusação de que há a politização da ciência - assim como do jornalismo - como se houvesse uma conjetura ideológica que emoldurasse todas as suas práticas, à esquerda especialmente.

Como alerta Lippmann (2010), podemos ser especialistas somente em alguns tópicos, entendendo a especialidade como "a multiplicação no número de aspectos que estamos preparados a descobrir, mais o hábito de descontar nossas expectativas". Enquanto para o ignorante todas as coisas são iguais, pois o exame tende a ser norteado de acordo com as qualidades ou defeitos pressupostos nos estereótipos, para o especialista, elas são altamente individuais, pois o olhar segue critérios que permitam individualizar os fenômenos e aprofundar a compreensão sobre eles, examinando todas as variáveis identificáveis em cada circunstância. Assim, "na maior parte dos casos nós não vemos em primeiro lugar, para então definir, nós definimos primeiro e então vemos" (LIPPMANN, 2010, p.85), indicando que, na relação com o mundo exterior, o indivíduo capta aquilo que sua cultura já o antecipou, de modo estereotipado, mesmo que a percepção se distancie do que, objetivamente, está diante de seus olhos. 0 que se vê e o que se recordará é o que as referências de cada indivíduo lhe ensinaram a ver, incluindo os limites desse ver. Os estereótipos não são neutros e, quando fixados, a própria atenção é dirigida aos fatos que o apoiam, bem como à recusa daquilo que os contradizem. Eles "estão carregados de preferência, cobertos de afeto ou aversão, ligados aos temores, avidez, fortes desejos, orgulho, esperança" (LIPPMANN, 2010, p.115), por isso a maior parte das coisas é imaginada antes de ser experimentada.

Para a pós-verdade, "a ciência silencia e a ideologia faz falar. Ali onde o multiculturalismo valorizava a polifonia de vozes e a diversidade de acentos, a pós-verdade se eleva como trovão da ordem" (DUNKER, 2017, p.39). Assim, pode-se compreender de onde derivam termos como pseudociência e pseudointelectual para desqualificar algumas ciências e cientistas, especialmente as humanas. Na pós-verdade, está nas relações intersubjetivas a negação da multiculturalidade e da diferença, com a expressão do ódio e da violência. Nessa diretriz, a liberação da "censura", caracterizada por comentários racistas e homofóbicos, por exemplo, ocorre por haver a sensação de que há uma plateia composta por pessoas que pensam da mesma forma, aplaudem 
e reverberam as ideias verbalizadas. Esse processo conduz ao choque de massas vocais, composto pelo encontro de certezas de pessoas que visam a dominação pelo eco.

Para Sacramento e Paiva (2020), a suspensão da censura moralizante na formação de agrupamentos estabelecidos em torno de objetivos comuns, potencializada na internet e nas redes sociais on-line, libera pulsões e animalidade. Enquanto manifestações de incivilidade extrema, estão relacionadas com a incapacidade de aceitação das diferenças, sejam elas religiosas, de gênero, ideológicas ou de outra natureza. Nessa direção, as campanhas de desinformação, alimentadas por fake news e impulsionadas em plataformas on-line, são particularmente preocupantes porque não permanecem on-line. Nos EUA, conforme relata Wichowski (2020), os crimes de ódio aumentaram por três anos consecutivos, de acordo com 0 Federal Bureau of Investigations (FBI). Somente na cidade de Nova York houve aumento de $67 \%$ no primeiro trimestre de 2019, se comparado ao ano anterior.

Em relação ao Brasil, Dunker (2017, p.38-39) diz haver a expansão de um "novo irracionalismo brasileiro - com sua disposição predatória contra professores, estudantes, artistas, aposentados e demais "parasitas" que não sabem o "valor do trabalho" e que não aceitam as "verdades óbvias" - presume uma geografia simples e bem dividida entre ciência e religião, ordem e baderna, fatos e opiniões", transferindo a autoridade dessas instituições para a opinião ancorada numa razão universal, que dispensa a análise complexa de múltiplas variáveis.

Lippmann (2010) endossa a ideia de que o estranho tende a ser evitado, pois o novo tensiona o fundamento das certezas, 0 absolutismo da visão. Nesse plano, o outro é visto como o inimigo, a quem dificilmente se credita a honestidade, numa oposição que tende à dicotomia, o bem e o mal, o verdadeiro e o falso, e os acontecimentos, especialmente aqueles que contrariam os códigos, passam a ser interpretados como resultado dessa vilania: se perdeu a eleição, as urnas eletrônicas foram fraudadas; se é investigado por lavagem de dinheiro, é vítima de perseguição política. Assim, "medos antigos, reforçados por medos recentes, coadunam num emaranhado de medos onde qualquer coisa que é temida é a causa de qualquer coisa que é receada" (LIPPMANN, 2010, p.145). Ao sentir ódio por algo, há a associação como causa e efeito de outras coisas que também são odiadas ou temidas e, mesmo que não haja conexão entre elas, estão unidas na mesma emoção.

A irracionalidade associada à sustentação das "verdades óbvias" não se dá pela supressão completa dos fatos objetivos, pois envolve a combinação arquitetada "de observações corretas, interpretações plausíveis e fontes confiáveis em uma mistura que é, no conjunto, absolutamente falsa e interesseira" (DUNKER, 2017, p.38), explorando os preconceitos do interlocutor e que induzem à confirmação de teses tendenciosas. Em complemento, combinação que conta com o apoio e a amplificação algorítmica em plataformas on-line. A verdade objetiva dos fatos se torna menos relevante no ambiente discursivo da pósverdade do que 0 apelo às crenças pessoais e às emoções, em detrimento da formação de atitudes "críticas", baseadas no pressuposto de que o outro poderia estar nos enganando, assim como poderíamos, nós mesmos, estar nos enganando.

Diante dos aspectos até aqui colocados, resume-se que a disseminação de fake news se insere num projeto de constituição de algo que, hoje, denomina-se por vários autores de pós-verdade e que consiste na deslegitimação das instituições que historicamente ancoravam o que era compreendido como verdade nas sociedades democráticas. Trata-se, pois, de um projeto de poder sustentado por um cariz ideológico conservador em nome do mercado, da família, da religião e em negação às diferenças e à formação do pensamento crítico, aspectos estes tão necessários à convivência democrática e ao debate constitutivo da opinião pública. Nesse cenário, é preciso compreender as estruturas e a ideologia que rege o funcionamento das plataformas on-line, os quais condicionam previamente os processos comunicacionais que acionam as temáticas de interesse público. 


\section{CONSIDERAÇÕES FINAIS}

0 conceito de opinião pública, apesar de centenário, ainda exige a discussão permanente. Fruto de uma ampla problematização, ganhou espaço em diversas áreas do conhecimento, incluindo a comunicação. Os avanços tecnológicos e a sociedade digital complexificam ainda mais o conceito, pois promovem uma nova lógica comunicativa, permeada pelo fenômeno das fake news e inscrita num panorama de "verdades preferenciais".

Nos últimos tempos, fomos percebendo que a (des)informação pode se converter em uma arma para promover ou dissolver processos democráticos e, porque não dizer, as próprias instituições que "guardam" nossa democracia. É preciso observar que a desinformação contida por trás de movimentos antidemocráticos, por exemplo, pode estar sendo inflamada intencionalmente. Neste caminho, conforme sentencia Wichowski (2020), perdemos a vontade de conhecer pessoas que podem pensar diferentes de nós. Perdemos a confiança nas instituições e valores tidos como inquestionáveis, tais como a liberdade, passam a ser mais facilmente negociáveis.

Diante desses aspectos, o desafio desse texto esteve em lançar luz sobre o processo de plataformização nesse contexto de rupturas sociais e democráticas, articulado com a discussão sobre o reforço das convicções e o esvaziamento da argumentação num modelo de comunicação mais passional e menos racional, no debate público contemporâneo, característico do fenômeno da pós-verdade. A problemática em tela reúne aspectos estéticos e retóricos da comunicação, as motivações individuais elou coletivas entre crença e razão, além das lógicas de funcionamento e penetração gradual das plataformas nas estruturas sociais, para entender os impactos sobre a compreensão da realidade e, consequentemente, a constituição da opinião pública.

Por fim, tangenciando-se uma perspectiva tecnicista, trata-se, pois, de reconhecer a necessidade de compreender as estratégias de comunicação na sua articulação técnica e social, considerando o apoio de mecanismos de registro, organização e personalização de informações originárias da interação do usuário com as plataformas on-line, para situar e avançar a discussão acerca dos limites e possibilidades para a opinião pública nas sociedades democráticas contemporâneas, especialmente no Brasil.

\section{REFERÊNCIAS}

DIGILABOUR. A Sociedade da Plataforma: entrevista com José van Dijck. São Leopoldo, 6 mar. 2019. Disponível em: http:// bit.ly/2NNWThr. Acesso em: 6 maio 2020.

DOURADO, Tatiana; GOMES, Wilson. 0 que são, afinal, fake news, enquanto fenômeno de comunicação política? In: CONGRESSO DA ASSOCIAÇÃO BRASILEIRA DE PESQUISADORES EM COMUNICAÇÃO E POLÍTICA, 8., 2019, Brasília, DF. Anais [...]. Brasília, DF: UnB, 2019. p.1-25.

DUNKER, Christian. Subjetividade em tempos de pós-verdade. In: DUNKER, Christian et al. Ética e pós-verdade. Porto Alegre: Dublinense, 2017. p.9-41.

GOMES, Wilson. Da discussão à visibilidade. In: GOMES, Wilson; MAIA, Rousiley. Comunicação e democracia: problemas \& perspectiva. São Paulo: Paulus, 2008. p.117-162. 
HABERMAS, Jürgen. Mudança estrutural na Esfera Pública: investigações quanto a uma categoria da sociedade burguesa. Tradução Flavio R. Kothe. 2.ed. Rio de Janeiro: Tempo Brasileiro, 1984.

LIPPMANN, Walter. Opinião pública. Petrópolis: Vozes, 2010.

NOELLE-NEUMANN, Elisabeth. Pesquisa eleitoral e clima de opinião. Opinião Pública, Campinas, v.1, n.2, p.74-97, 1993.

SACRAMENTO, Igor; PAIVA, Raquel. Fake news, WhatsApp e a vacinação contra febre amarela no Brasil. MATRIZes, São Paulo, v.14, n.1, p.79-97, 2020.

VAN DIJCK, José; POELL, Thomas; DE WALL, M. The Platform Society. public values in a connected world. Oxford: Oxford University Press, 2018.

WICHOWSKI, Alexis. "What unites us": how the angry few hijack public opinion and why institutions must intervene to save democracy. In: FARIAS, Luis Alberto; LEMOS, Else; REBECHI, Cláudia Nociolini. Opinião pública, comunicação e organizações. convergências e perspectivas contemporâneas. São Paulo, SP: Abrapcorp, 2020. p.18-31. 